\title{
Modeling Changes in U.S. Monetary Policy with a Time-Varying Nonlinear Taylor Rule*
}

\author{
Anh D.M. Nguyen, Efthymios G. Pavlidis, and David A. Peel ${ }^{\dagger}$
}

February 2018

\begin{abstract}
The monetary economics literature has highlighted four issues that are important in evaluating U.S. monetary policy since the late 1960s: (i) time variation in policy parameters, (ii) asymmetric preferences, (iii) real-time nature of data, and (iv) heteroskedasticity. In this paper, we exploit advances in sequential monte carlo methods to estimate a time-varying nonlinear Taylor rule that addresses these four issues simultaneously. Our findings suggest that U.S. monetary policy has experienced substantial changes in terms of both the response to inflation and to real economic activity, as well as changes in preferences. These changes cannot be captured adequately by a single structural break at the late 1970s, as has been commonly assumed in the literature, and play a non-trivial role in economic performance.
\end{abstract}

JEL Classification: C32, E52, E58

Keywords: Real-time data, Taylor rule, Monetary policy rules, Particle filter, Asymmetric objective, Time-varying parameter model, Stochastic volatility.

*Authors are thankful to the editor and the referee for their comments. Authors also thank Konstantinos Theodoridis, Ivan Paya, John Barrdear, Jeremy Chiu, Mihnea Constantinescu, Timo Teräsvirta, Julien Chevallier and participants at the 3rd International Workshop on Financial Markets and Nonlinear Dynamics (Paris, France), the 2017 Royal Economic Society Annual conference (Bristol, UK), the 2015 Money Macro and Finance conference (Cardiff, UK) and the Bank of Lithuania seminar (Vilnius, Lithuania) for comments and suggestions. Nguyen acknowledges the support of the UK Economic and Social Research Council [ES/J500094/1]. The views expressed in this paper are those of the authors and do not necessarily reflect those of the Bank of Lithuania or the Eurosystem.

${ }^{\dagger}$ Nguyen (corresponding author): Economics Department, Bank of Lithuania and Faculty of Economics, Vilnius University, Lithuania, Email: anguyen@lb.lt; Pavlidis: Department of Economics, Lancaster University, Lancaster, UK, Email: e.pavlidis@lancaster.ac.uk; and Peel: Department of Economics, Lancaster University, Lancaster, UK, Email: d.peel@lancaster.ac.uk. 


\section{Introduction}

In a seminal paper, Clarida, Galí, and Gertler (2000) (CGG hereafter) show that changes in monetary policy played an important role in the performance of the post-war US economy. By estimating monetary policy reaction functions before and after Volcker's appointment as Fed's Chairman in 1979, they find that in the pre-Volcker period monetary policy was greatly accommodative with interest rates rising less than expected inflation, thus violating the Taylor principle; while, in the Volcker-Greenspan era, monetary policy became strongly anti-inflationary with increases in expected inflation being associated with larger increases in the policy instrument. ${ }^{1}$ This change in monetary policy has been highlighted by several authors as one of the main causes of the remarkable decline in the variability of output and inflation after the mid-1980s - the so-called Great Moderation.

However, the view that monetary policy led to the Great Moderation is not universal. Many economists argue that what actually changed between the pre- and post-Volcker periods were not macroeconomic policies but luck -in the sense that the shocks hitting the economy became smaller and more infrequent. Most notably, Sims and Zha (2006) examine a battery of multivariate regime-switching models for the U.S. economy and find that the model that fits the data best is a linear in mean model with time-varying error variances. On this basis, the authors conclude that the documented changes before and after 1979 can be attributed to the failure to allow properly for heteroscedasticity. Recent studies, such as Mumtaz and Zanetti (2013) and Born and Pfeifer (2014), also confirm that the volatility of monetary policy shocks have changed overtime.

In addition to allowing for heteroskedastic errors, the empirical monetary economics literature has criticized the approach of CGG in other three dimensions. The first is related to the nature of changes in policy parameters, and, in particular, the fact that a single structural break may be too restrictive when considering long periods of data. For instance, Alcidi et al. (2011) use a logistic smooth transition regression (LSTR) model developed by Teräsvirta (1994) and provide empirical evidence of policy regime changes even during the Greenspan era. Also based on the Teräsvirta (1994)'s LSTR, Martin and Milas (2010) document changes in the conduct of monetary policy during the 1983-2004 period. Furthermore, Cogley and Sargent (2001, 2005) and Boivin (2006) argue that changes in the Fed's monetary policy may be gradual rather than discrete and, therefore, a more flexible modeling approach, such as a time-varying parameter (TVP) framework, is required to study the historical conduct of monetary policy. See, e.g, Teräsvirta et al. (2010) and Teräsvirta (2018 forthcoming) for discussions on TVP models.

The second criticism of the CGG approach is related to the data employed for the estimation of policy reaction functions. CGG fit their model to revised data, but, as

\footnotetext{
${ }^{1}$ The basic logic behind this principle is that when inflation increases, monetary policy needs to raise the real interest rate in order to slow the economy and reduce inflationary pressures (Woodford, 2001). Also, Woodford (2003) shows that this condition (or some close variant forms of it) must be satisfied for the determinacy of most existing macroeconomic models. Lubik and Schorfheide (2004) formally test for indeterminacy of U.S. monetary policy in a New Keynesian framework and find that the post-1982 U.S. monetary policy is consistent with determinacy, whereas the pre-Volcker policy is not, therefore confirming the findings of CGG.
} 
Orphanides (2001) points out, using information, which was not available to the monetary authorities when making decisions, to evaluate monetary policy may lead to false inference. By fitting a forward-looking Taylor rule, similar to that of CGG, to real time data on inflation and unemployment, Orphanides (2002) finds no significant differences between monetary policy in the 1970s and the period after. Following the work of Orphanides, real-time data have been widely used in the investigation of historical monetary policy, not only in the US but also in many other countries. Examples include Boivin (2006), Molodtsova et al. (2008), Martin and Milas (2010), Nikolsko-Rzhevskyy (2011) and Lee et al. (2013), among many others.

Finally, a number of studies have argued that the preferences of central bankers may be asymmetric with respect to inflation and/or real activity (see, e.g., Nobay and Peel, 2003; Ruge-Murcia, 2003). This asymmetry can occur from several sources. For instance, if a central banker is devoted solely to inflation targeting, a deflationary bias may arise, which will make the response of monetary policy to changes in the state of the economy highly asymmetric. On the other hand, a central banker may behave as having an inflationary bias when trying to exploit the output-inflation tradeoff. The existence of asymmetric preferences is supported by statements of policy makers such as that of Blinder (1998, pp.19-20): "in most situations the central bank will take far more political heat when it tightens pre-emptively to avoid higher inflation than when it eases pre-emptively to avoid higher unemployment." De Long (1997) and Nelson (2005) present extensive narrative evidence in favor of the notion of asymmetric preferences induced by politics during the 1970s. Dolado et al. (2004) provide empirical support for this type of asymmetric behavior. In addition, using the Luukkonen et al. (1988)'s non-linearity test, Surico (2007) rejects the null hypothesis of symmetric preferences of the Fed. ${ }^{2}$

In summary, the existing empirical literature highlights four issues as crucial in properly evaluating US monetary policy: time-variation in policy parameters, asymmetric preferences, heteroskedastic errors, and real-time data. This paper, for the first time, simultaneously takes all these issues into account. ${ }^{3}$ To do so, we derive a model specification as the discretionary outcome of the formal monetary policy design problem in which the central bank can display asymmetric preferences. We allow the coefficients of

\footnotetext{
${ }^{2}$ Asymmetric responses of monetary policy may also come from other sources which are not examined in our framework. For instance, Dolado et al. (2005) derive an asymmetric optimal policy by combing a quadratic loss function with a nonlinear Phillips curve. Nevertheless, they only find empirical support for this type of asymmetries for four European central banks but none for the Fed. Meanwhile, Meyer et al. (2001) show that episodes of heightened uncertainty about the NAIRU may warrant a nonlinear policy response to changes in the unemployment rate. Although we do not investigate this type of nonlinearities, we consider different measures of the natural rate of unemployment as shown in section 4.4.1 as robustness checks of our findings.

${ }^{3}$ Boivin (2006) is the first study that deals with time-variation in policy parameters, heteroskedastic errors, and real-time data. Although the issue of asymmetric preferences was not considered in that paper. Moreover, Boivin (2006) models heteroskedasticy with a single break in the variance at 1979 in the baseline model and two breaks at 1979 and 1982 in the robustness checks. However, as we shown below in Figure 5, such an approach with discrete breaks may not fully capture the changes in the variance. For example, in the 1970s, which Boivin (2006) considers as one regime, the variance was lower in the second half than the first half on the average.
} 
the derived policy rule to vary over time, as in Kim and Nelson (2006), in order to capture potential changes in policy parameters; and, we deal with heteroscedasticity by allowing the standard deviation of monetary policy innovations to follow a stochastic volatility process similar to Stock and Watson (2007) and Justiniano and Primiceri (2008). Finally, following Orphanides (2001), we use real-time Greenbook forecasts for estimation. The resulting econometric model is both time-varying and nonlinear with respect to parameters. As a consequence, the popular Kalman filter cannot be utilized for estimation. To overcome this obstacle, we adopt a novel Bayesian approach, namely particle filtering, which has gained popularity in economics and econometrics over recent year (see Creal (2012) and Teräsvirta et al. (2010, p. 229-231) for reviews and the references therein). The key idea of particle filtering is to represent the required posterior density function by a set of random samples with associated weights and to compute estimates based on these samples and weights (Ristic et al., 2004).

Our results suggest that substantial changes in the response to inflation and to real economic activity as well as in Fed's preferences have occurred over time. Regarding the pre-Volcker period, we find that the response to inflation was not uniformly weak, as typically assumed in the literature, with the Taylor principle being violated in the second half of the 1970s, but not in the period before (see, also, Cogley and Sargent, 2001, 2005; Boivin, 2006). This finding supports the point made by Boivin (2006) that the failure to properly account for the rich evolution of monetary policy seems to be the cause of conflicting results between CGG and Orphanides (2002). Moreover, our results are in favor of the notion of an inflationary bias, with the interest rate response in the preVolcker era being stronger for negative deviations of inflation from target in comparison to positive deviations of the same size, which can help explain the high levels of inflation in the 1970s. This result therefore confirms the importance of taking the asymmetric preferences into account when studying the historical conduct of U.S. monetary policy.

With respect to the post-Volcker era, we find considerable differences in the response of interest rate to inflation and to real activity between the 1980s-90s, and the period thereafter. In the former period, monetary policy responded strongly to inflation but weakly to real activity, in line with the findings of Kim and Nelson (2006) and CGG, which implies a concentration of the Fed on stabilizing inflation. In contrast, in the latter period, once inflation was stabilized, the Fed appears to have paid more attention to stabilizing real activity, while hardly responding to inflation. These results are broadly similar to Martin and Milas (2010) and Fernández-Villaverde et al. (2010, 2015).

The paper proceeds as follows. Section 2 discusses the formal monetary policy design problem in which the central bank's loss function is asymmetric with respect to inflation. Section 3 describes the empirical model with time-varying parameters and stochastic volatility. The same section outlines the particle-filtering estimation method. Section 4 presents the empirical results, and section 5 concludes. 


\section{The Theoretical Model}

The central bank chooses interest rates to minimize the present discounted value of its loss function which depends on the inflation gap, which is the difference between inflation and its target $\pi_{t}-\pi^{*}$, the output gap $y_{t}$, which is the gap between the actual output and the potential one, and the interest rate gap, which is the distance between the interest rate level and the target $i_{t}-i^{*}$ (Surico, 2007; Tillmann, 2011). Formally, the loss function takes the following form ${ }^{4}$

$$
L_{t}=\frac{e^{\alpha\left(\pi_{t}-\pi^{*}\right)}-\alpha\left(\pi_{t}-\pi^{*}\right)-1}{\alpha^{2}}+\frac{\mu}{2}\left(y_{t}\right)^{2}+\frac{\gamma}{2}\left(i_{t}-i^{*}\right)^{2}
$$

where $\alpha$ captures the asymmetry in the loss function with respect to inflation, $\mu$ and $\gamma$ are parameters representing the central bank's preferences towards the output gap and the deviation of the interest rate from its target. The preference to inflation is normalized to one. This specification of the loss function is called the linex function proposed by Varian (1975) and introduced to the optimal monetary policy literature by Nobay and Peel (2003).

The loss function (2.1) differs from the conventional quadratic set-up in the way it deals with inflation deviations. For $\alpha>0$, when inflation is above the target, the exponential term of the loss function $e^{\alpha\left(\pi_{t}-\pi^{*}\right)}$ dominates the linear term $\alpha\left(\pi_{t}-\pi^{*}\right)$, so the value of the loss function rises exponentially. However, if inflation is below the target, the linear term dominates the exponential term and the value of the loss function increases linearly. This implies that, for $\alpha>0$, positive deviations of inflation relative to the target are more costly than negative deviations. In this case, the central bank can be said to have deflationary bias. In contrast, for $\alpha<0$, negative deviations cause a greater loss than positive deviations. This case reflects the view of the central bank that deflation is more costly than inflation. Therefore, the central bank can be characterized as possessing inflationary bias. Another interesting feature is that when $\alpha$ approaches zero, the loss function becomes the common quadratic form. The quadratic loss function is thus a special case of the loss function (2.1).

The policy action is subject to the following constraints:

$$
\begin{gathered}
\pi_{t}=\beta E_{t} \pi_{t+1}+\kappa y_{t}+\varepsilon_{t}^{s}, \\
y_{t}=E_{t} y_{t+1}-\varphi\left(i_{t}-E_{t} \pi_{t+1}\right)+\varepsilon_{t}^{d} .
\end{gathered}
$$

The above expressions represent the equilibrium conditions of the standard New Keynesian model. The reader is referred to Woodford (2003, Chapter 3) and Galí (2008, Chapter 3) for a complete derivation. Equation (2.2) is the forward-looking Phillips

\footnotetext{
${ }^{4}$ Typically, the loss function of the households has a quadratic form derived as a second-order approximation to the utility losses experienced by the representative consumer as a consequence of deviations from the efficient allocation, e.g. Rotemberg and Woodford (1999). We deviate from such a framework in regard to the loss function of central bankers in order to investigate the possibility of their asymmetric behavior in policy-making. The suggested framework nests the popular quadratic loss function as a special case.
} 
curve, which builds on the Calvo-type staggered nominal price setting in which only a fraction of firms are allowed to reset their prices in any given period, whereas the others are constrained to keep their prevailing prices. Inflation in this setting depends on the current output gap and expected inflation. Equation (2.3) is the log-linearized consumption Euler equation which is derived from the household's optimal consumption decision and the market clearing condition. This equation shows that the current output gap depends on the expected future output gap and the real interest rate. A higher level of expected future output leads to a greater level of current output because of the consumption smoothing behavior, whereas a higher real interest rate lowers the current output owning to the intertemporal substitution of consumption. The interest elasticity $\varphi$ corresponds to the intertemporal elasticity of substitution. Finally, $\varepsilon_{t}^{s}$ and $\varepsilon_{t}^{d}$ are cost and demand disturbances.

\subsection{Asymmetric Policy Rule}

Central bankers conduct monetary policy to minimize the expected value of a loss criterion of the form

$$
W=E_{t} \sum_{i=1}^{\infty} \beta^{i} L_{t+i},
$$

subject to the forward-looking Phillips curve (2.2) and the IS curve (2.3).

It is assumed that central bankers are unable to make any kind of commitment over the course of future monetary policy. Instead, they take private sector expectations as given and execute policy under discretion. According to CGG, this scenario seems to accord best with reality. Given this assumption, the Lagrangian of the policy problem is written as follows

$$
\begin{gathered}
\underset{\pi_{t}, y_{t}, i_{t}}{\operatorname{Min}} E_{t}\left\{\frac{e^{\alpha\left(\pi_{t}-\pi^{*}\right)}-\alpha\left(\pi_{t}-\pi^{*}\right)-1}{\alpha^{2}}+\frac{\mu}{2}\left(y_{t}\right)^{2}+\frac{\gamma}{2}\left(i_{t}-i^{*}\right)^{2}\right. \\
\left.-\phi_{t}^{\pi}\left(\pi_{t}-\kappa y_{t}-\varepsilon_{t}^{s}\right)-\phi_{t}^{y}\left(y_{t}+\varphi i_{t}-\varepsilon_{t}^{d}\right)\right\}
\end{gathered}
$$

where $\phi_{t}^{\pi}$ and $\phi_{t}^{y}$ are the Lagrange multipliers. Solving this problem, we obtain the following approximated optimal policy rule ${ }^{5}$

$$
i_{t}=i^{*}+\frac{\varphi \kappa}{\gamma} E_{t}\left(\pi_{t}-\pi^{*}\right)+\frac{\alpha \varphi \kappa}{2 \gamma} E_{t}\left(\pi_{t}-\pi^{*}\right)^{2}+\frac{\mu \varphi}{\gamma} E_{t} y_{t}
$$

The expectations operator in (2.5) implies that the policy action is taken before the realization of inflation and the output gap. Therefore, the central bank chooses the interest rate at time $t$ based on its expectations on the relevant variables conditional on the information available at that period. Let $\pi_{t \mid t}, \sigma_{\pi_{t} \mid t}^{2}, y_{t \mid t}$ be the nowcasts of inflation, the

\footnotetext{
${ }^{5}$ The derivation of the optimal rule can be found in Online Appendix 1.
} 
variance of inflation, and the output gap, respectively. Equation (2.5) can be re-written as

$$
i_{t}=a_{0}+a_{1} \pi_{t \mid t}+a_{2} \sigma_{\pi_{t} \mid t}^{2}+a_{3} y_{t \mid t} .
$$

where $a_{0}=i^{*}-\frac{\varphi \kappa}{\gamma} \pi^{*}, a_{1}=\frac{\varphi \kappa}{\gamma}, a_{2}=\frac{\alpha \varphi \kappa}{2 \gamma}$, and $a_{3}=\frac{\mu \varphi}{\gamma}$. Note that when $\alpha$ approaches zero, so does $a_{2}$, the reaction function (2.6) collapses to a standard interest rate rule in which the interest rate responds symmetrically to the deviations of inflation and output from their targets. Equation (2.6) therefore nests the symmetric form as a special case. In the next section, we describe how to fit (2.6) to data.

\section{The Empirical Model}

The empirical counterpart of the theoretical model (2.6) is written as follows

$$
\begin{gathered}
i_{t}=\rho_{t} i_{t-1}+\left(1-\rho_{t}\right)\left(a_{0, t}+a_{1, t} \pi_{t \mid t}+a_{2, t} \sigma_{\pi_{t} \mid t}^{2}+a_{3, t} y_{t \mid t}\right)+\exp \left(a_{4, t}\right) \varepsilon_{t}, \\
\rho_{t}=\frac{1}{1+\exp \left(-a_{5, t}\right)} \\
a_{k, t}=a_{k, t-1}+\exp \left(\sigma_{a_{k}}\right) \varepsilon_{a_{k}, t}, \quad k=0,1, \ldots, 5
\end{gathered}
$$

where $\varepsilon_{t} \sim$ i.i.d.N $(0,1)$ and $\varepsilon_{a_{k}, t} \sim$ i.i.d.N $(0,1)$ for $k=0,1, \ldots, 5$. The innovations, $\varepsilon_{t}$ and $\varepsilon_{a_{k}, t}$ for $k=0,1, \ldots, 5$, are independent.

This empirical model deals with the four issues raised in the literature on modeling monetary policy. First, its specification takes into consideration the asymmetric issue in monetary policy. Second, parameters are allowed to vary over time to capture potential changes in the conduct of monetary policy. ${ }^{6}$ Third, the issue of heteroscedasticity is treated by modeling the standard deviation of monetary policy innovations as stochastic volatility process, a popular mean to model heteroscedasticity in the literature (see, e.g., Cogley and Sargent, 2005; Primiceri, 2005; Stock and Watson, 2007). Finally, the model is fitted with real-time data, as will be discussed below. It is also worth noting other features of the model. Following CGG, the lag of interest rate is included as an explanatory variable to capture the observed smoothing of interest rate. Moreover, the smoothing parameter $\rho_{t}$ is constrained to be positive but smaller than unity and then transformed to the real line by the logit transformation as in Kim and Nelson (2006). For the time-variation of parameters, it is assumed to follow random walk dynamics similar to Cogley and Sargent (2005) and Boivin (2006), among many others.

\footnotetext{
${ }^{6}$ With a time-varying intercept, we allow for the possibility of changes in the equilibrium interest rate and inflation target. Although it is worth noting that the evidence of changes in inflation target is mixed. For instance, Favero and Rovelli (2003) find that the implicit inflation target is higher in the pre-Volcker period than the post- Volcker one. However, according to Clarida et al. (2000), such a difference is not significant when taking into account the change of the response to inflation and, thus, differences in monetary policy between the pre- and post-1979 does not simply reflect differences in the target inflation rate.
} 
Substituting (3.2) into (3.1) yields

$$
\begin{array}{r}
i_{t}=\frac{1}{1+\exp \left(-a_{5, t}\right)} i_{t-1}+\frac{\exp \left(-a_{5, t}\right)}{1+\exp \left(-a_{5, t}\right)}\left(a_{0, t}+a_{1, t} \pi_{t \mid t}+a_{2, t} \sigma_{\pi_{t} \mid t}^{2}+a_{3, t} y_{t \mid t}\right) \\
+\exp \left(a_{4, t}\right) \varepsilon_{t},
\end{array}
$$

The combination of (3.3) and (3.4) generates a state-space system. In this system, the state model (3.3) describes the evolution of the state vector $\mathbf{x}_{t}=\left[a_{0, t}, a_{1, t}, a_{2, t}, a_{3, t}, a_{4, t}, a_{5, t}\right]^{\prime}$ and the measurement model (3.4) relates the noisy measurement $i_{t}$ to the state. In order to facilitate the analysis, the state-space system is written in its probabilistic form as follows

$$
\begin{aligned}
& \mathbf{x}_{t}=h\left(\mathbf{x}_{t-1}, \mathbf{w}_{t} ; \varpi\right), \\
& i_{t}=g\left(\mathbf{x}_{t}, \varepsilon_{t} ; \varpi, \mathbf{A}_{t}\right),
\end{aligned}
$$

where $\mathbf{w}_{t}=\left[\varepsilon_{0, t}, \varepsilon_{1, t}, \varepsilon_{2, t}, \varepsilon_{3, t}, \varepsilon_{4, t}, \varepsilon_{5, t}\right]^{\prime}$ is the vector of state noises, which has a multivariate normal distribution with zero mean and identity covariance matrix, $\varpi=\left[\sigma_{a_{0}}, \sigma_{a_{1}}, \sigma_{a_{2}}, \sigma_{a_{3}}, \sigma_{a_{4}}, \sigma_{a_{5}}\right]^{\prime}$, and $\mathbf{A}_{t}=\left[i_{t-1}, \pi_{t \mid t}, y_{t \mid t}, \sigma_{\pi_{t} \mid t}^{2}\right]^{\prime}$ includes observed inputs. To ease notation, in what follows we drop $\mathbf{A}_{t}$ without any loss of generality. The functions $h(\cdot)$ and $g(\cdot)$ come from the equations that characterize the behavior of the model, i.e. (3.3) and (3.4).

Our objective is to estimate the evolution of state variables given the sequence of received measurement. In order to do so, it is required to construct the posterior probability density function of the state vector. However, the constraint on the smoothing parameter and the stochastic volatility of monetary policy shocks generate nonlinearities in the system, preventing us from using the well-known Kalman filter and, thus, complicating the estimation. To deal with the nonlinearities, we apply the approach called the particle filter, which is proposed by Gordon et al. (1993). The key idea of particle filtering is to represent the required posterior density function by a set of random samples with associated weights and to compute estimates based on these samples and weights (Ristic et al., 2004).

Let $X_{t}=\left\{\mathbf{x}_{j}, j=0, \ldots, t\right\}$ and $I_{t}=\left\{i_{j}, j=0, \ldots, t\right\}$ represent the sequences of all states and available measurements, respectively, up to time $t$. The joint posterior density at time $t$ is denoted by $p\left(X_{t} \mid I_{t}\right)$ and its marginal is $p\left(\mathbf{x}_{t} \mid I_{t}\right)$. Let $\left\{X_{t}^{k}, \omega_{t}^{k}\right\}_{k=1}^{N}$ denote a random measure that describes the joint posterior $p\left(X_{t} \mid I_{t}\right)$ where $\left\{X_{t}^{k}, k=1, \ldots, N\right\}$ is a set of support points with associated weights $\left\{\omega_{t}^{k}, k=1, \ldots, N\right\}$. The weights are normalized to sum to unity. Thus, the joint posterior distribution at $t$ can be approximated by

$$
p\left(X_{t} \mid I_{t}\right) \approx \sum_{k=1}^{N} \omega_{t}^{k} \delta\left(X_{t}-X_{t}^{k}\right),
$$

where $\delta($.$) is the Dirac delta measure. The normalized weights \omega_{t}^{k}$ are chosen by applying the principle of importance sampling in which $X_{t}^{k}$ is drawn from an importance density 
$q\left(X_{t} \mid I_{t}\right)$

$$
\omega_{t}^{k} \propto \frac{p\left(X_{t}^{k} \mid I_{t}\right)}{q\left(X_{t}^{k} \mid I_{t}\right)} .
$$

If the importance density is chosen so that it can be factorized by

$$
q\left(X_{t} \mid I_{t}\right) \triangleq q\left(\mathbf{x}_{t} \mid X_{t-1}, I_{t}\right) q\left(X_{t-1} \mid I_{t-1}\right)
$$

then the samples $X_{t}^{k} \sim q\left(X_{t} \mid I_{t}\right)$ can be achieved by augmenting each of the existing samples $X_{t-1}^{k} \sim q\left(X_{t-1} \mid I_{t-1}\right)$ with the new state $\mathbf{x}_{t}^{k} \sim q\left(\mathbf{x}_{t} \mid X_{k-1}, I_{k}\right)$. At time step $t$ when a measurement $i_{t}$ becomes available, the posterior density $p\left(X_{t} \mid I_{t}\right)$ can be updated from $p\left(X_{t-1} \mid I_{t-1}\right)$ by

$$
\begin{aligned}
p\left(X_{t} \mid I_{t}\right) & =\frac{p\left(i_{t} \mid X_{t}, I_{t-1}\right) p\left(X_{t} \mid I_{t-1}\right)}{p\left(i_{t} \mid I_{t-1}\right)} \\
& \propto p\left(i_{t} \mid \mathbf{x}_{t}\right) p\left(\mathbf{x}_{t} \mid \mathbf{x}_{t-1}\right) p\left(X_{t-1} \mid I_{t-1}\right) .
\end{aligned}
$$

Substituting (3.9) and (3.11) into (3.8) yields the weight update equation

$$
\omega_{t}^{k} \propto \omega_{t-1}^{k} \frac{p\left(i_{t} \mid \mathbf{x}_{t}^{k}\right) p\left(\mathbf{x}_{t}^{k} \mid \mathbf{x}_{t-1}^{k}\right)}{q\left(\mathbf{x}_{t}^{k} \mid X_{t-1}^{k}, I_{t}\right)} .
$$

By using the bootstrap filtering proposed by Gordon et al. (1993), we evaluate the importance weights attached to each particle as follows

$$
\omega_{t}^{k} \propto \omega_{t-1}^{k} p\left(i_{t} \mid \mathbf{x}_{t}^{k}\right)
$$

Given these weights, the marginal posterior density $p\left(\mathbf{x}_{t} \mid I_{t}\right)$ can be approximated as

$$
p\left(\mathbf{x}_{t} \mid I_{t}\right) \approx \sum_{k=1}^{N} \omega_{t}^{k} \delta\left(\mathbf{x}_{t}-\mathbf{x}_{t-1}^{k}\right)
$$

Ristic et al. (2004) shows that as $N \rightarrow \infty$ the approximation (3.12) approaches the true marginal posterior density $p\left(\mathbf{x}_{t} \mid I_{t}\right)$. Based on this posterior density, we estimate the state vector as its conditional mean. To deal with the degeneracy problem, i.e. the variance of importance weights can only increase over time (Ristic et al., 2004), we use the systematic resampling method because it is easy to apply and outperforms other resampling schemes in most cases (Doucet and Johansen, 2009).

Moreover, a by-product of the particle filter is that the likelihood can be approximated by using the weights $\omega_{t}^{i}:{ }^{7}$

$$
p\left(I_{T} ; \varpi\right) \approx \prod_{i=1}^{T}\left(\sum_{i=1}^{N} \omega_{t}^{i}\right) .
$$

\footnotetext{
${ }^{7}$ We use 10,000 particles. This number delivered a good compromise between accuracy and time to calculate the likelihood.
} 
Once the likelihood is evaluated, we can use the maximum likelihood approach to estimate $\varpi$, the vector of time-invariant parameters. $^{8}$

Note that particle filtering generates an approximation to the likelihood function that is not differentiable with respect to the parameters because of the inherent discreteness of the resampling step. Therefore, Newton's type algorithms, based on derivatives, are not applicable. We instead use the covariance matrix adaption evolutionary strategy (CMAES) to obtain the maximum-likelihood estimates of $\varpi$. This optimization algorithm is designed to cope with objective functions that are non-linear, non-convex, rugged, and multimodal (Hansen, 2011; Andreasen, 2010).

\section{Data and Empirical Results}

\subsection{Data}

The estimation of the state-space system described by (3.3) and (3.4) requires data for the nominal interest rate, expected inflation, expected variance of inflation, and expected output gap. For the nominal interest rate, we use the effective federal funds rate extracted from the FRED economic database. For the expected value of inflation, we use the Greenbook forecasts of the current-quarter annualized percentage change in the GNP or GDP deflation.

Regarding the expected variance of inflation, this variable is obviously not directly observable. The data and the methodology used for its construction are discussed in the following subsection. With respect to the real economic activity measure, we use the unemployment gap in place of the output gap. The reason for this choice is twofold. First, because of repeated changes in the base year, no consistent time series of predicted real GDP or GNP can be derived from the Greenbook over the sample (Boivin, 2006). Second, maximum employment is one of the objectives of monetary policy clearly written in the Federal Act, thus it is natural to include the unemployment rate directly into the policy function. The unemployment gap is defined as the difference between the natural rate of unemployment and the forecasted unemployment rate so that the sign of the unemployment gap is consistent with that of the conventionally-defined output gap. While the forecast of contemporaneous unemployment rate is collected directly from the Greenbook, the natural rate of unemployment is measured by a 5-year moving average of unemployment rate as in Bernanke and Boivin (2003). We name this proxy the 5-year moving average unemployment gap. The dataset spans the period 1965Q4 to 2007Q4. The start of the sample corresponds to the first period predictions were recorded in the Greenbook. The sample ends prior to the federal funds rate hitting the zero lower bound in 2008 .

\subsection{Expected Variance of Inflation}

Bollerslev (1986) and Dolado et al. (2004) among others obtain the conditional variance

\footnotetext{
${ }^{8}$ Online Appendix 3 presents how to derive the approximation of the likelihood function.
} 
of inflation from ex-post revised data by using a dynamic model with $\operatorname{GARCH}(1,1)$ disturbances. We employ a similar framework that accommodates the use of real-time data. In particular, for each time period, we estimate

$$
\begin{gathered}
\pi_{t}=c+\sum_{i=1}^{n} \beta_{i} \pi_{t-i}+\zeta y_{t}+\epsilon_{t}, \\
\epsilon_{t}=\sigma_{\pi, t} z_{t}, \\
\sigma_{\pi, t}^{2}=\alpha_{0}+\alpha_{1} \epsilon_{t-1}^{2}+\beta_{1} \sigma_{\pi, t-1}^{2} .
\end{gathered}
$$

by using information available at time $t$, and, based on the fitted GARCH process (4.3), we forecast the contemporaneous variance of inflation (see Teräsvirta (2009) for a brief survey of univariate GRACH models). ${ }^{9}$ Note that the specification (4.1), which has been proven fairly successful in capturing the dynamics of inflation in the U.S. economy (see, e.g., Rudebusch, 2001), can be derived using our theoretical framework by substituting $E_{t} \pi_{t+1}$ in (2.2) by a linear combination of the lags of inflation. ${ }^{10}$ Thus, it has theoretical underpinnings.

To enhance our GARCH-based estimations, we exploit the fact that data on inflation and unemployment are available at a higher frequency. Specifically, we use monthly data for the construction of the expected variance of inflation spanning the period 1948M1 to 2007M9. We assume that the variance of inflation of quarter $t$ is nowcasted using the information available at the first month of that quarter. ${ }^{11}$ This assumption is in line with the Greenbook forecasts because they are often published by the end of the first month or the middle of the second month of a quarter. The procedure for forecasting the contemporaneous variance of inflation series with four steps is described in detail in Appendix A.1. We also examine alternative proxies of the output gap and different numbers of lags of inflation used in Equation (4.1) and summarize all the results in Table 1 in Appendix A.1. The results show that those forecasts are very similar, thus corroborating our constructed series. The forecasts also remain similar if we substitute the real activity variable $y_{t}$ in (4.1) by a linear combination of its lags.

Figure 1 present one of the measures of the expected variance of inflation estimated by applying the above procedure with three lags of inflation $(n=3)$ and the output gap $\left(y_{t}\right)$ proxied by the 5-year moving average unemployment gap. Overall, we observe that, as well documented in the literature, the expected variance of inflation has changed considerably over time. Specifically, it increased substantially in the mid-1970s, then

\footnotetext{
${ }^{9}$ We use the popular GARCH model instead of the SV model due to the large computational costs associated with the estimation of the latter in a recursive framework. As a robustness check, we compare the estimates of the two models using several sub-samples of the data, and do not find any substantial differences.

${ }^{10}$ We can not use the one-quarter-ahead Greenbook forecasts of inflation directly as a measure of $E_{t} \pi_{t+1}$ in (4.1) because there is not enough data to estimate the model and to conduct forecasts, say, at the vintage $1965 \mathrm{Q} 4$.

${ }^{11}$ The estimation and forecast are conducted repeatedly on the rationale of real-time data, so the coefficients of the GARCH process can vary overtime. For this reason, we do not show the estimates associated with the GARCH process; they are, however, available upon request.
} 


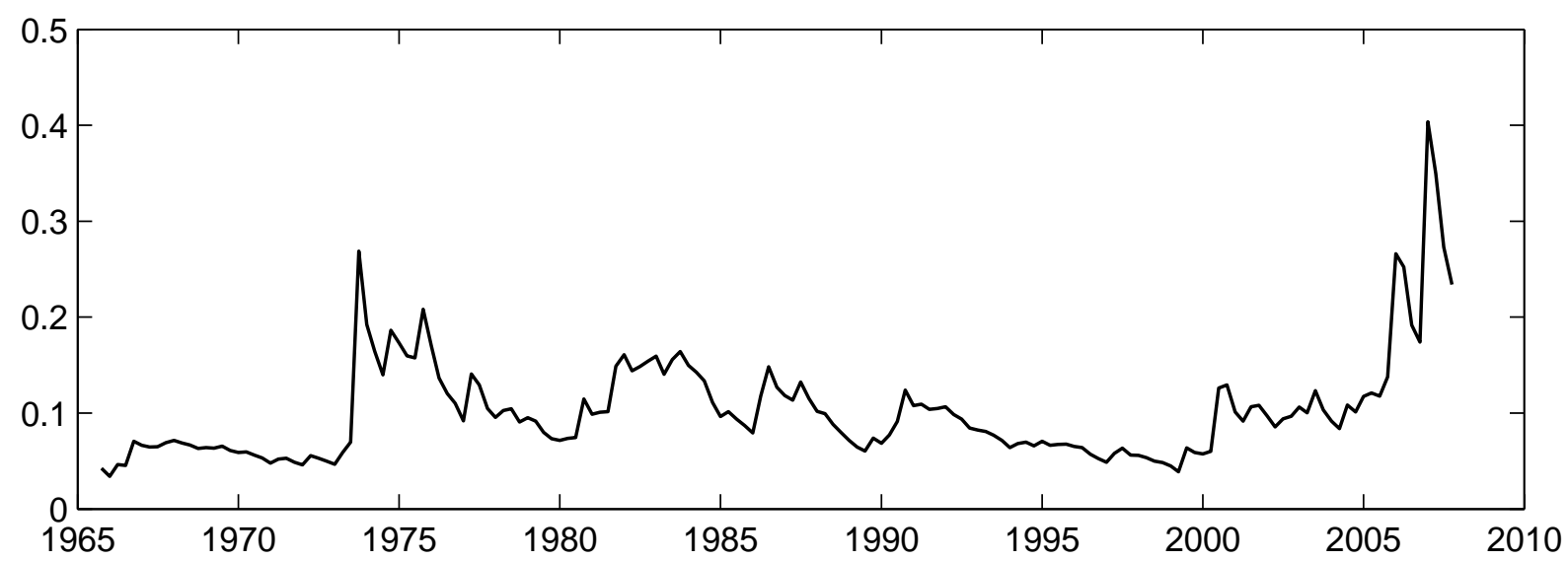

Figure 1: Expected Variance of Inflation

Notes: The expected variance of inflation is computed by applying the procedure described in Section 4.2, with the number of lags of inflation set equal to three and the output gap $y_{t}$ proxied by the five-year moving average gap in Equation (4.1).

reduced gradually to its late 1960s - early 1970s level by 2000s, but rose again after that and reached a peak in 2007Q1.

\subsection{Results for the Baseline Model}

We proceed to analyze the estimation results, with a particular interest in the responses of the interest rate to real activity (unemployment gap), inflation and the variance of inflation. ${ }^{12}$ Figure 2 reports the response to real activity. We observe that the response was positive and statistically significant in the 1970s, in line with the findings of Clarida et al. (2000). It then decreased and became insignificant in the second half of the 1980s. In the early 1990s, the response to real activity experienced a substantial increase from just above 1.0 in 1990 to approximately 2.0 from 1995 onwards, which implies that the Fed paid more attention to real activity since then. Martin and Milas (2010) find that the response to real activity is around 2.0 for the 1983-2004 period. ${ }^{13}$ A similar value is also reported in Blinder and Reis (2005) for the Greenspan period. Moreover, Blinder and Reis (2005) find that monetary policy under the Greenspan regime responded stronger to unemployment than the policy under the Volcker period. Kim and Nelson (2006) also obtain a similar pattern when estimating a time-varying parameter model using ex-post data.

\footnotetext{
${ }^{12}$ The estimates of time-invariant parameters are presented in Appendix A.2.

${ }^{13}$ Gerdesmeier and Roffia (2005) consider the conduct of monetary policy in the euro area and document that the estimate of the response to output is higher when using real-time output data as opposed to ex-post output data. Gerberding et al. (2005) also obtain a similar finding for the Bundesbank.
} 


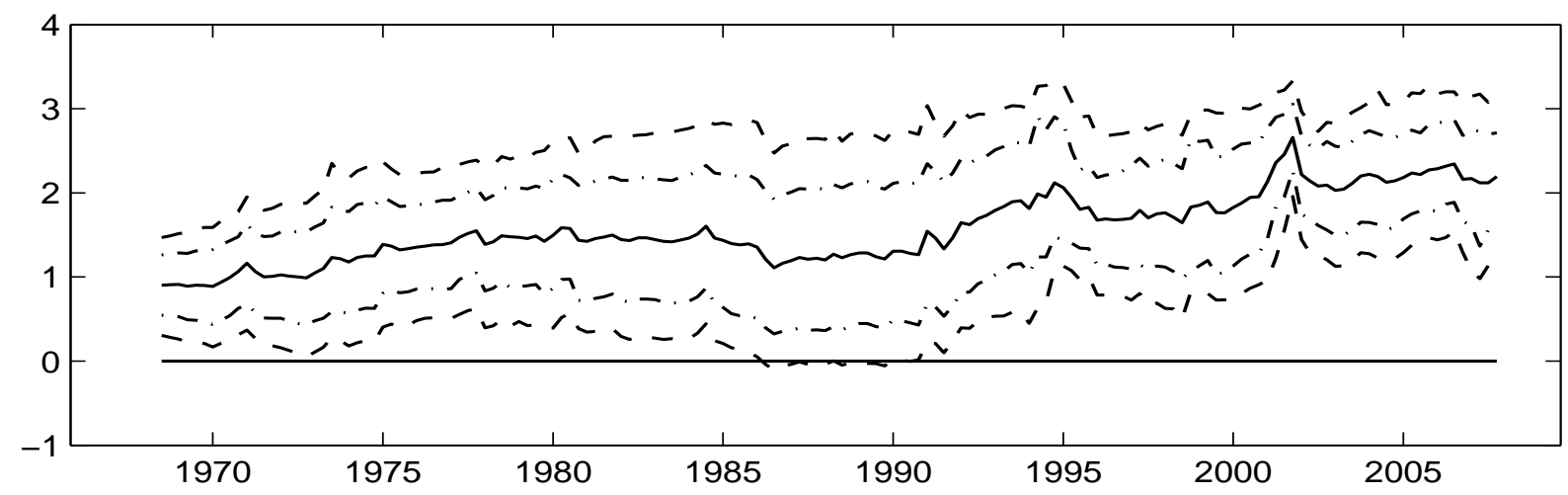

Figure 2: Response to Real Activity

Note: Dashed lines are 68\% and 90\% percentile intervals.

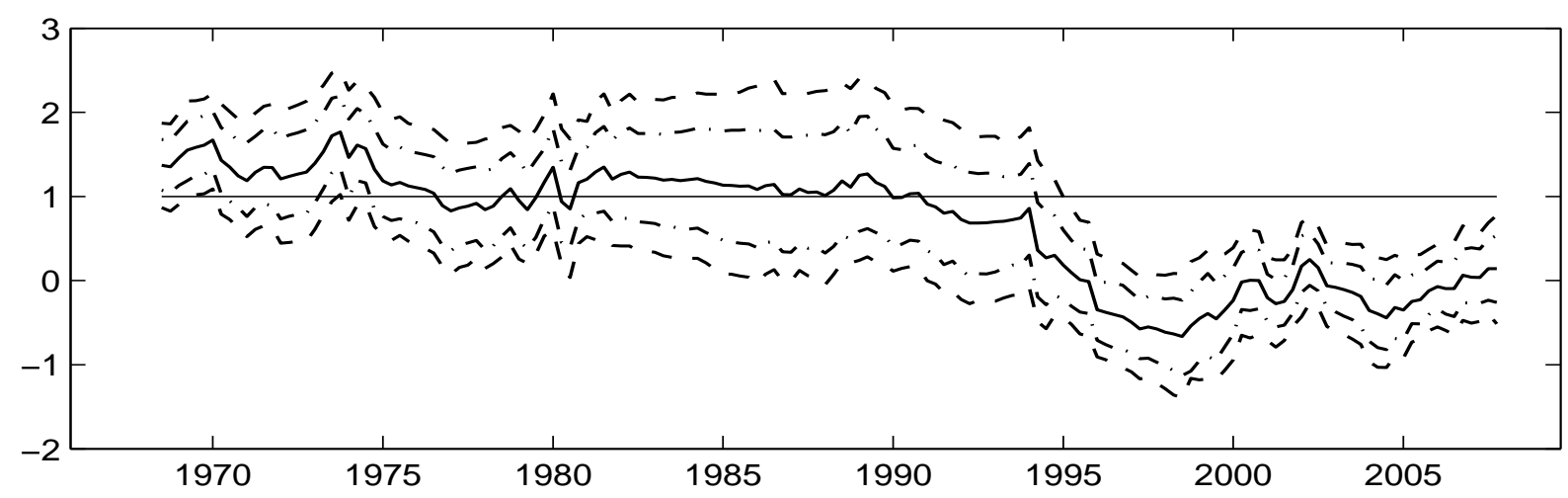

Figure 3: Response to Inflation

Note: Dashed lines are $68 \%$ and $90 \%$ percentile intervals.

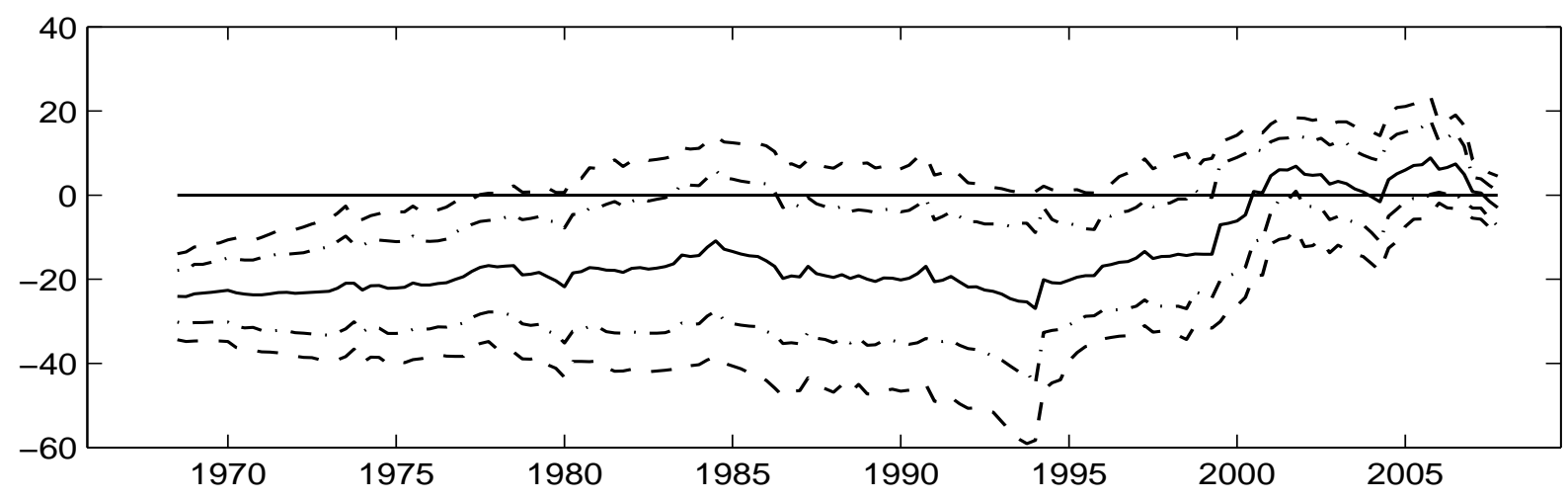

Figure 4: Response to Inflation Variance

Note: Dashed lines are 68\% and 90\% percentile intervals. 
The response to inflation is depicted in Figure 3. The pre-1979 response to inflation was not uniformly weak as typically assumed. It was above unity until 1975, then decreased considerably and went below unity, particularly between 1976 and 1978. This property of the pre-1979 monetary policy is consistent with Boivin (2006) and Cogley and Sargent (2001, 2005). Based on narrative evidence, Romer and Romer (1989) also conclude that the actual commitment of the Fed to combat inflation appeared to have been weak in the 1976-1978 period. As soon as Paul Volcker was appointed Chairman of the Fed in the third quarter of 1979Q3, the response to inflation became strong. However, the main shift under the Volcker's tenure seems to have happened during the 1981-1982 period. The inflation coefficient was mainly above unity to the early 1990s, then fell and has become not significant by the mid-1990s. ${ }^{14}$ This result is inline with Fernández-Villaverde et al. (2010, 2015) who estimate a DSGE model for the U.S. economy with stochastic volatility and parameter drifting in the Taylor rule and find that the post-1990 response to inflation was weak. ${ }^{15,16}$ Alternatively, the insignificant response to inflation can be explained from a statistical perspective. If inflation was close to the implicit target in the post-1990 period as suggested by Martin and Milas (2010), it might be hard to identify the response of interest rate to inflation due to lack of variability.

We now turn to the response to inflation variance. Figure 4 shows that this response was negative and statistically significant in the pre-1979 period, but became statistically insignificant in the post-1979 period. This suggests that in the pre-1979 period the Fed behaved as if having asymmetric preferences - in the sense that negative inflation gaps were considered more costly than positive gaps of the same absolute size. On the other

\footnotetext{
${ }^{14}$ For narrative evidence, see Online Appendix 8.

${ }^{15}$ Fernández-Villaverde et al. (2015) show that the relevant part of the solution of the model for determinacy is only the linear first-order component which depends on the mean policy response, not the current value of the response. The authors find that the estimated mean policy response to inflation is greater than one, therefore, guaranteeing the local determinacy of the equilibrium.

${ }^{16} \mathrm{~A}$ similar result can be derived from a model with the opportunistic approach.The idea of the opportunistic approach is that if inflation stays within a range around a target, the interest rate should not respond to inflation, but rather should wait for external circumstances to bring inflation back to the target. In this case, the focus is on stabilizing output (Orphanides and Wilcox, 2002). By estimating a non-linear Taylor rule for the U.S. monetary policy during the 1983-2004 period to test the opportunistic model developed by Orphanides and Wilcox (2002), Martin and Milas (2010) find that there is no response of interest rates to inflation when inflation is within 1 per cent of the intermediate target but a strong response when inflation is further from the intermediate target. The authors also point out that expected inflation since the early 1990s seldom moved away from the zone of inaction. According to Granger (2008), any non-linear model can be approximated by a time-varying parameter linear model, which therefore helps to account for the similarities in the results of Martin and Milas (2010) and ours when it comes to monetary policy during this episode.
} 


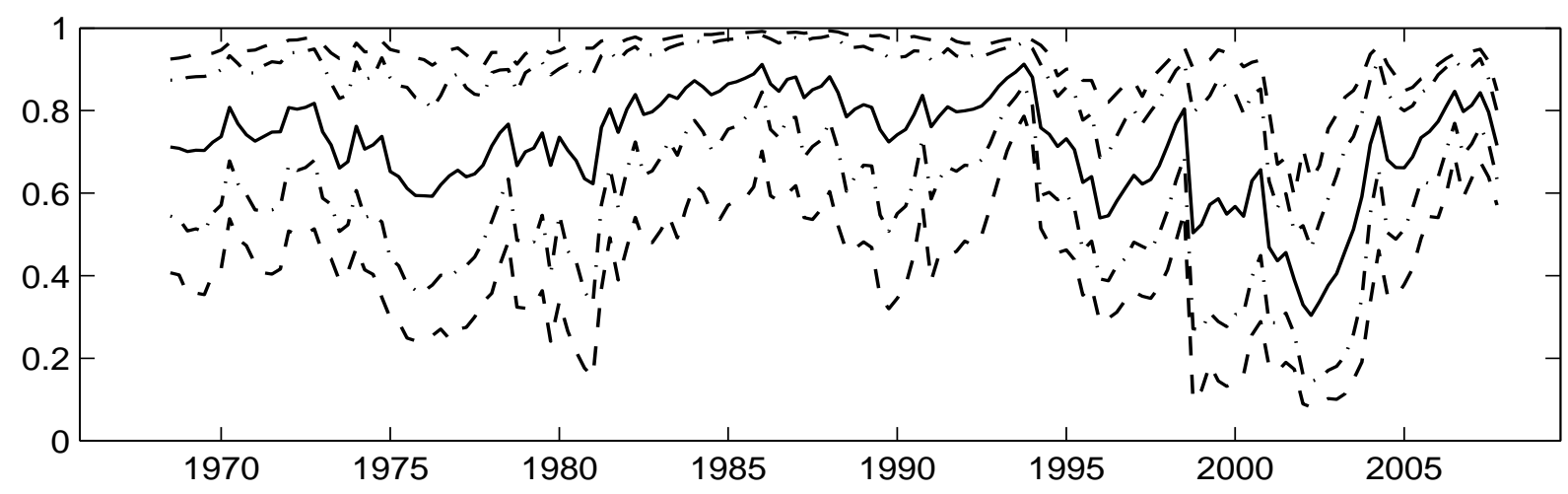

(a) Time-varying Degree of Interest Rate Smoothing

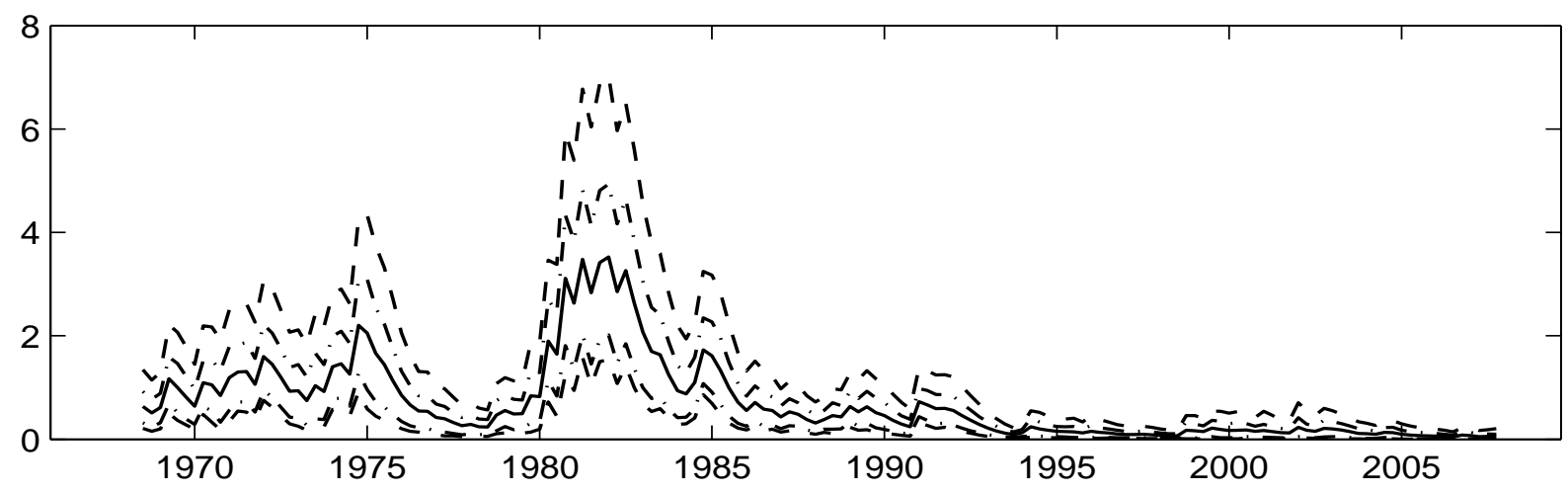

(b) Stochastic Volatility

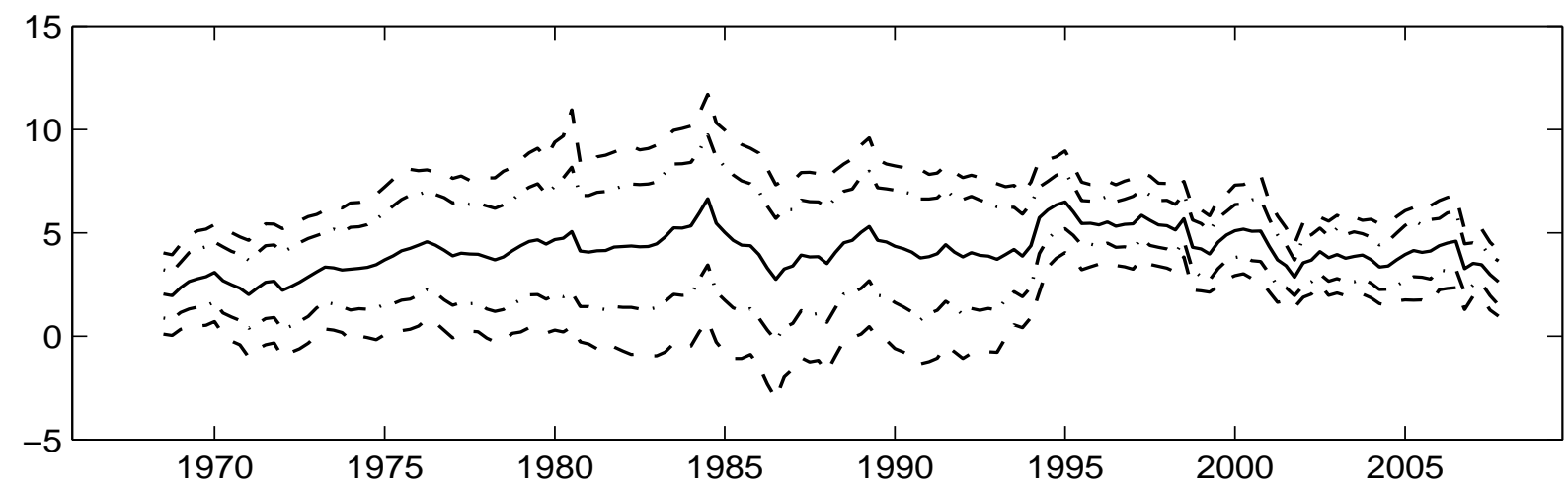

(c) Time-varying Intercept

Figure 5: Interest Rate Smoothing Degree, Stochastic Volatility, and Intercept Note: Dashed lines are $68 \%$ and $90 \%$ percentile intervals.

hand, the post-1979 monetary policy seems to be characterized by symmetric rules. ${ }^{17,18}$

\footnotetext{
${ }^{17}$ These results are broadly similar to Surico (2007) who investigates changes in asymmetric preferences
} 
In summary, through the lens of our model, inflation stabilization can be attributed to both changes in the direct response to inflation, as suggested by Clarida et al. (1999, 2000), Cogley and Sargent (2001, 2005), and Boivin (2006), and changes in preferences, as put forward by Cukierman and Gerlach (2003), Dolado et al. (2004), and Surico (2007). Regarding the former, the response to inflation was weak in the second half of the 1970s, which likely contributed to the high level of inflation during this era. In contrast, the strong response to inflation in the 1980s played a role in bringing inflation down and keeping it stable. It appears that the Fed's preferences changed in the late 1970s as well. Prior to that, the Fed's behavior was seemingly asymmetric in the sense that negative inflation deviations from the target are considered to be more costly than positive ones of the same magnitude. This asymmetry led to inflationary bias in the conduct of monetary policy, which might have accounted for the great inflation during this decade. On the contrary, we do not find evidence of such an inflationary bias from the early 1980s onwards.

The smoothing parameter, the standard deviation of monetary policy shocks, and the intercept also vary over the sample as displayed in Figure 5. The smoothing parameter was large and stable from the mid-1980s to the mid-1990s, which suggests that the interest rate was persistent during these periods. It then decreased reaching a trough in the early 2000s, before returning to the high level of persistence at the end of the sample. Concerning the standard deviation of monetary policy shocks, this variable has declined and also become more stable since the mid-1980s. This result therefore highlights the importance of taking heteroscedasticity into account as argued by Sims and Zha (2006). Regarding the intercept, as in line with Kim and Nelson (2006), it was high in the early 1980s and consistently statistically significant from the mid 1990s onwards.

\subsection{Robustness Checks}

We study the robustness of the results of the baseline model in two dimensions: alternative measures of real activity and another model specification with asymmetric preferences with respect to both inflation and real activity.

\subsubsection{Real Activity Measures}

In the baseline model, we proxy the output gap by the difference between a 5 -year moving average of unemployment rate and the expected contemporaneous unemployment rate. Because there is no guarantee that this proxy corresponds to the real activity measure

of the Fed before and after 1979. The inflationary bias in the pre-1979 period in Surico (2007) is caused by an asymmetric response to changes in the real activity with the interest rate response to output contractions being larger than the response to output expansions of the same magnitude. However, different with our results, Surico (2007) does not find the evidence of asymmetric preferences with respect to inflation. Recall that Surico (2007) estimates with ex-post revised data for the pre- and post-1979 subsamples, therefore not taking into account the issue of real-time data and the nature of changes in policy parameters which are considered in our models. In section 4.4.2, we consider a model with asymmetric preferences to both inflation and real activity

${ }^{18}$ Additional discussions about changes in the Fed's preference are provided in Online Appendix 8. 
perceived by policymakers, it is important to investigate how robust the results are with respect to different measures of the output gap.

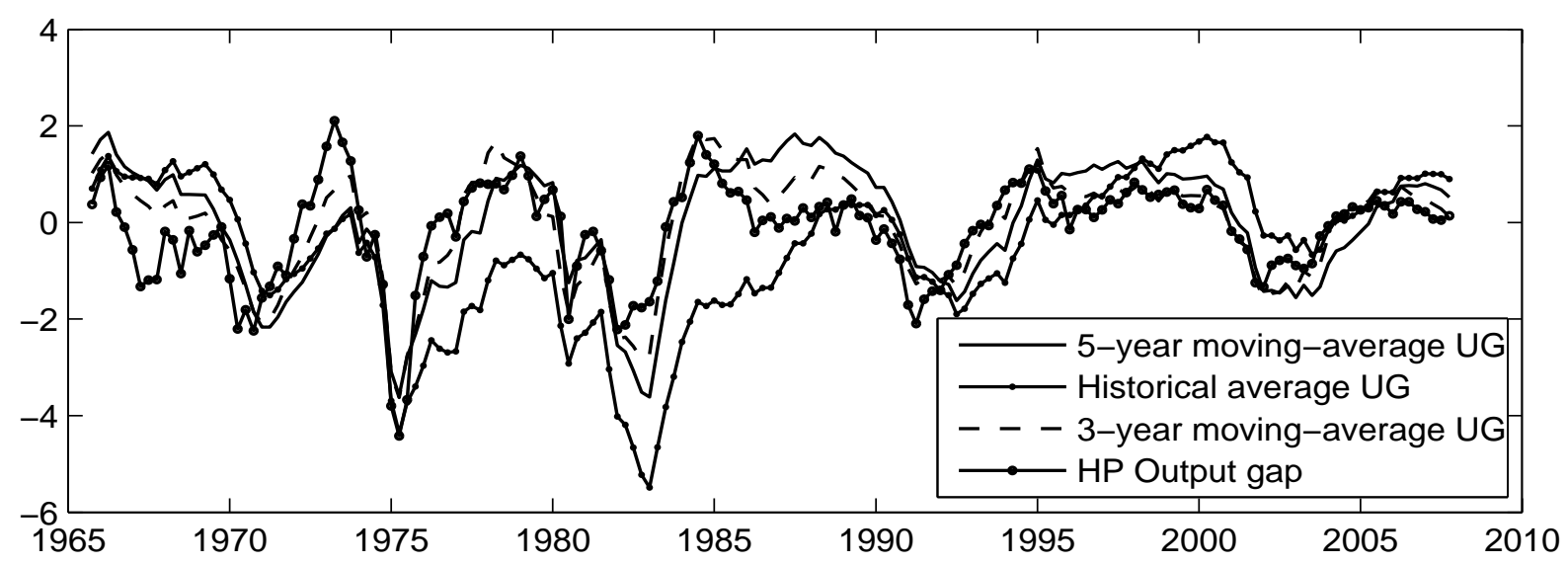

Figure 6: Measures of Real Activity for the Contemporaneous Quarter.

First, we consider two alternative measures of the natural rate of unemployment: a historical average and a 3-year moving average, leading to the two different measures of unemployment gap. The figures are not shown to save space, but the readers can find them in Online Appendix 5. We observed that the response to inflation follows a similar path regardless of the measure used. In terms of the response to real activity, the coefficient corresponding to the 3-year moving average unemployment gap was not statistically different from zero in the 1980s. On the contrary, the coefficient for the historical average unemployment gap was statistically significant over the sample - though only marginally significant in the second half of the 1980s. The results for both measures affirm that the Fed has responded stronger to real activity since the early 1990s. With respect to the coefficient on inflation variance, this was negative and significant in the 1970s, but switched to insignificant since the early 1980s. Overall, these results are similar to those of the baseline model.

We have so far considered the unemployment rate as a proxy for the output gap. In this robustness check, we re-estimate our model using the HP output gap, and then compare the results obtained with those in the baseline model. The construction of the expected contemporaneous real-time HP output gap series is described in Online Appendix 4. Figure 6 shows the constructed series together with the above measures of unemployment gap. As can be seen in the figure, the HP output gap series shows a similar trend with the measures based on unemployment. Moreover, the results for the state space system based on the HP output gap are similar with those documented in the baseline model (See Online Appendix 5). That is, the results are not sensitive to the output gap measures. 


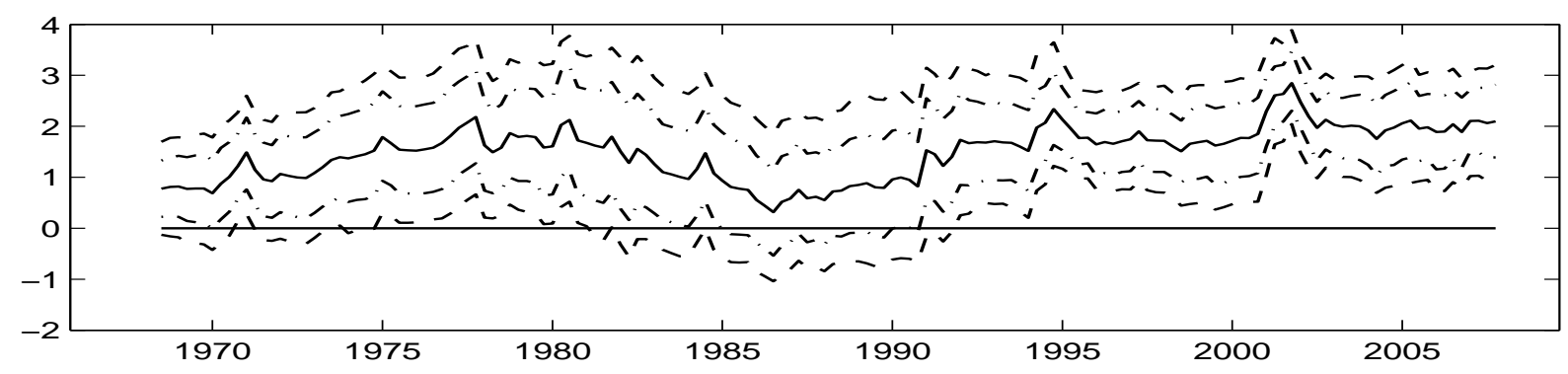

(a) Response to Real Activity

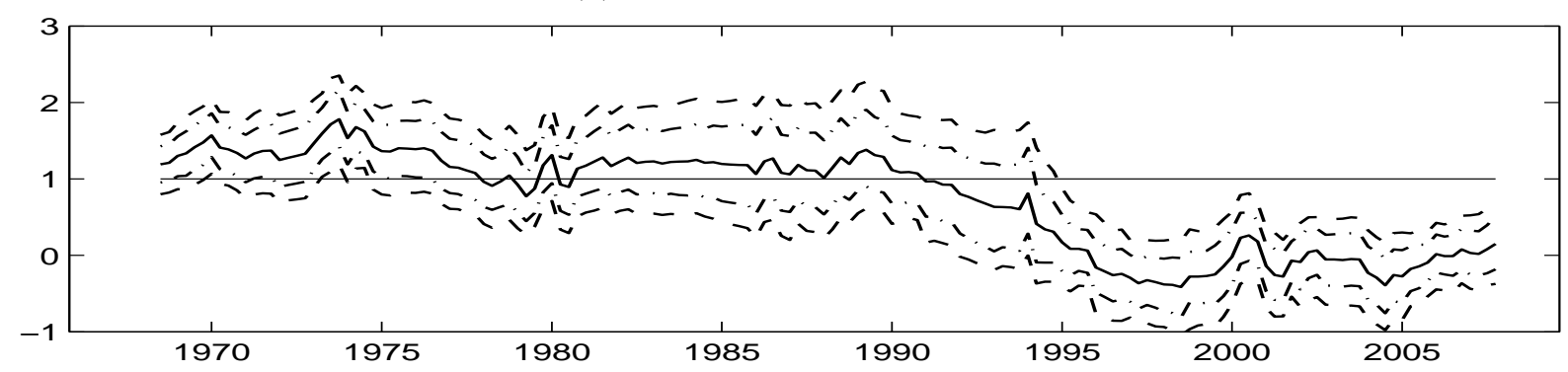

(b) Response to Inflation

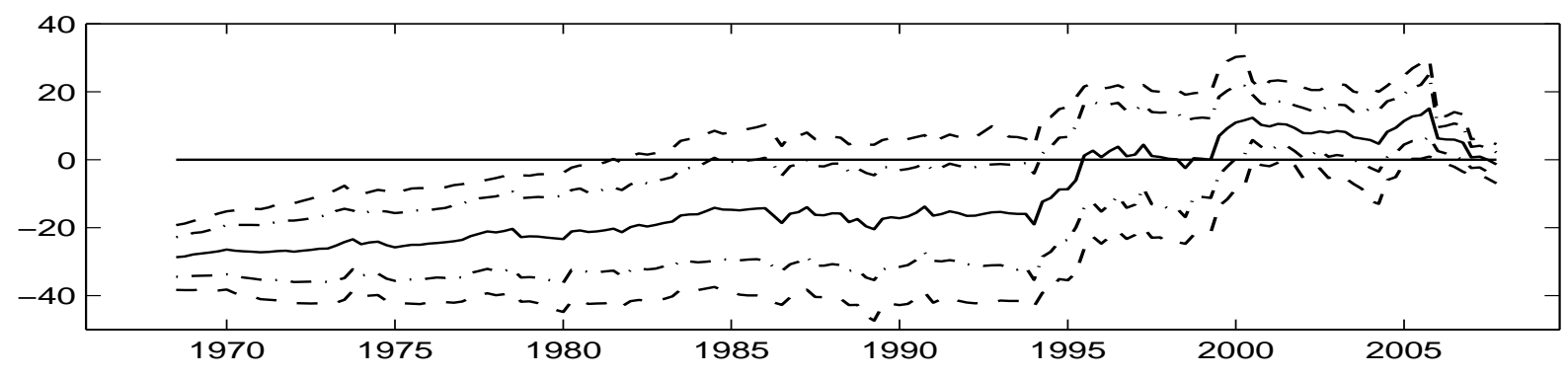

(c) Response to Inflation Variance

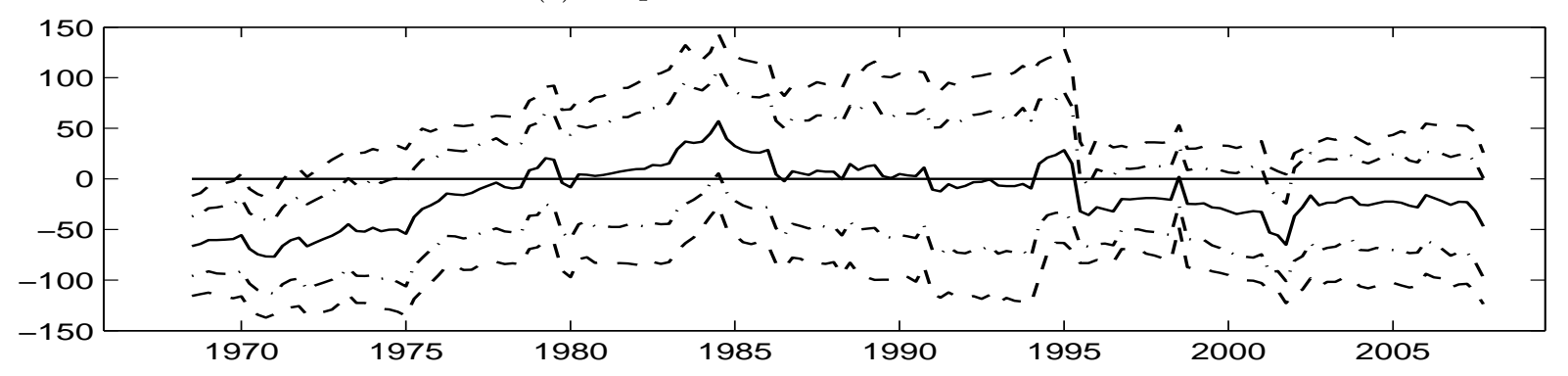

(d) Response to Output Gap Variance

Figure 7: Robustness Check with Asymmetric Preferences to Both Inflation and Output Gap

Note: Broken lines are $68 \%$ and $90 \%$ percentile intervals. 


\subsubsection{Asymmetric Preferences to Both Inflation and Real activity}

So far, we have considered asymmetric preferences with respect to inflation. However, the central bank may also react asymmetrically to real activity. For instance, a negative output/unemployment gap may be considered more costly than a positive gap of the same absolute size, causing interest rate to react more strongly to negative than positive gaps. ${ }^{19}$ This kind of asymmetry is studied in Ruge-Murcia (2003) and Cukierman and Gerlach (2003). For this reason, we modify the loss function in Equation (2.1) to include a linex function of the output gap as follows ${ }^{20}$

$$
L_{t}=\frac{e^{\alpha\left(\pi_{t}-\pi^{*}\right)}-\alpha\left(\pi_{t}-\pi^{*}\right)-1}{\alpha^{2}}+\mu\left(\frac{e^{\lambda y_{t}}-\lambda y_{t}-1}{\lambda^{2}}\right)+\frac{\gamma}{2}\left(i_{t}-i^{*}\right)^{2},
$$

where $\lambda$ captures the asymmetry in the loss function with respect to the output gap and other notations are the same as in (2.1). The central bankers are therefore allowed, but not required, to weight differently positive and negative deviations of inflation and output from the target values.

In this setting, the interest rate responds to inflation, unemployment gap, the variance of inflation and the variance of unemployment gap. ${ }^{21}$ The corresponding empirical model is then given by

$$
\begin{aligned}
i_{t} & =\frac{1}{1+\exp \left(-b_{6, t}\right)} i_{t-1}+\frac{\exp \left(-b_{6, t}\right)}{1+\exp \left(-b_{6, t}\right)}\left(b_{0, t}+b_{1, t} \pi_{t \mid t}+b_{2, t} \sigma_{\pi_{t} \mid t}^{2}\right. \\
& \left.+b_{3, t} y_{t \mid t}+b_{4, t} \sigma_{y_{t} \mid t}^{2}\right)+\exp \left(b_{5, t}\right) \varepsilon_{t}
\end{aligned}
$$

and the state vector becomes $\mathbf{x}_{t}=\left[b_{0, t}, b_{1, t}, b_{2, t}, b_{3, t}, b_{4, t}, b_{5, t}, b_{6, t}\right]^{\prime}$. The estimation of (4.5) requires the data of the expected variance of unemployment gap which is not available. We also use the GARCH model as above to construct this series. ${ }^{22}$ Other variables remain as in the baseline model.

Figure 7 presents the time-varying parameter results. It is apparent that the response to inflation, unemployment gap, and the variance of inflation are essentially the same with those in the baseline model. For the response to the variance of unemployment gap, the estimate also indicates an inflationary bias in the early 1970s, i.e. monetary policy responded stronger to negative unemployment gap than positive ones. Overall, the results are again in line with those documented in the baseline model.

\footnotetext{
${ }^{19}$ Negative output gap implies that output is below the potential output and negative unemployment gap means that unemployment rate is above the natural rate of unemployment.

${ }^{20} \mathrm{~A}$ similar loss function is considered in Surico (2007).

${ }^{21}$ Online Appendix 6 presents how to derive the approximated optimal policy rule under this specification.

${ }^{22}$ The dynamics of unemployment gap is derived from the IS equation, in which the expected inflation and unemployment gap are substituted by the linear combinations of their lags, with GARCH $(1,1)$ disturbances. See the details of the construction in Online Appendix 7.
} 


\section{Conclusion}

This paper analyzed how the conduct of U.S. monetary policy has changed since the late 1960s by simultaneously accounting for time-variation in policy parameters, heteroscedastic disturbances, asymmetric preferences, and real-time data. Our findings show that the evolution of monetary policy since the late 1960s has been rich in terms both of the response to inflation and real activity, and of preferences. Specifically, the Fed behaved like having asymmetric preferences, which induced an inflationary bias, in the pre-Volcker period, but changed to symmetric preferences in the post-Volcker era. Regarding the response to inflation, we found that it was strong only in the first half of the 1970s and the 1980s. On the other hand, the response to real economic activity was found to be weak in the 1980s. Overall, the estimated changes assign a nontrivial role of monetary policy in economic performance. 


\section{A Appendix}

\section{A.1 Forecasting the Contemporaneous Variance of Inflation}

We detail the procedure to forecast the contemporaneous variance of inflation series as follows:

Step 0, Initiation: We start with the $1965 Q 4$ period, set $i \rightsquigarrow 1965 Q 4$.

Step 1, Estimation: Let $I_{i}$ be the information set at time $i$ which includes available monthly inflation and the unemployment gap to the last month of the quarter $i-1$. Given $I_{i}$, Equation (4.1) is estimated with $\operatorname{GARCH}(1,1)$ errors.

Step 2, Forecast: Based on the estimated-GARCH process, we forecast the conditional variances of inflation for the three months of quarter $i$. Take the average of those forecasts and save it as $\sigma_{\pi_{i} \mid I_{i}}^{2}$.

Step 3, Termination: If $i \neq 2007 Q 4$, move to the next period $i=i+1$ and follow step 2. Otherwise, the procedure stops and we collect the expected variance of inflation $\sigma_{\pi_{i} \mid I_{i}}^{2}$ for $i=1965 Q 4, \ldots, 2007 Q 4$.

Table 1 report the means, the standard deviations and the correlation matrix of different estimates of the expected variance of inflation by applying the four-step procedure outlined above. The measures are different in terms of the number of lags of inflation $(n)$ and the measure of output gap $\left(y_{t}\right)$ which are used in Equation (4.1).

Table 1: Summary Statistics for Forecasts of Inflation Variance: 1965Q4-2007Q4

\begin{tabular}{ccccccc}
\hline & $\mathbf{M}_{0}$ & $\mathbf{M}_{1}$ & $\mathbf{M}_{2}$ & $\mathbf{M}_{3}$ & $\mathbf{M}_{4}$ & $\mathbf{M}_{5}$ \\
Means & 0.102 & 0.100 & 0.104 & 0.102 & 0.099 & 0.098 \\
$\begin{array}{c}\text { Standard deviations } \\
\text { Correlation matrix }\end{array}$ & 0.055 & 0.056 & 0.059 & 0.058 & 0.051 & 0.052 \\
$\mathbf{M}_{0}$ & 1.000 & 0.994 & 0.993 & 0.991 & 0.992 & 0.988 \\
$\mathbf{M}_{1}$ & 0.994 & 1.000 & 0.984 & 0.995 & 0.987 & 0.995 \\
$\mathbf{M}_{2}$ & 0.993 & 0.985 & 1.000 & 0.993 & 0.978 & 0.973 \\
$\mathbf{M}_{3}$ & 0.991 & 0.995 & 0.993 & 1.000 & 0.978 & 0.984 \\
$\mathbf{M}_{4}$ & 0.992 & 0.987 & 0.978 & 0.978 & 1.000 & 0.994 \\
$\mathbf{M}_{5}$ & 0.988 & 0.995 & 0.973 & 0.984 & 0.994 & 1.000 \\
\hline
\end{tabular}

Notes: The measure $\mathbf{M}_{0}$ is associated with three lags of inflation $n=3$ and the output gap $y_{t}$ proxied by the five-year moving average unemployment gap. For $\mathbf{M}_{1}, n=6$ and $y_{t}$ proxied by the five-year moving average unemployment gap. For $\mathbf{M}_{2}, n=3$ and $y_{t}$ proxied by the historical average unemployment gap. For $\mathbf{M}_{3}, n=6$ and $y_{t}$ proxied by the historical average unemployment gap. For $\mathbf{M}_{4}, n=3$ and $y_{t}$ proxied by the three-year moving average unemployment gap. Finally, for $\mathbf{M}_{5}, n=6$ and $y_{t}$ proxied by the three-year moving average unemployment gap. 


\section{A.2 Estimates of Time-Invariant Parameters}

The estimates of time-invariant parameters are presented in Table 2

Table 2: Means and Standard Deviations of Time-Invariant Parameters

\begin{tabular}{ccc}
\hline Parameters & Means & Standard deviations \\
\hline$\sigma_{a_{0}}$ & -0.86 & 0.11 \\
$\sigma_{a_{1}}$ & -2.22 & 0.08 \\
$\sigma_{a_{2}}$ & 0.63 & 0.11 \\
$\sigma_{a_{3}}$ & -2.23 & 0.14 \\
$\sigma_{a_{4}}$ & -1.10 & 0.07 \\
$\sigma_{a_{5}}$ & -1.28 & 0.08 \\
\hline
\end{tabular}

Notes: The table presents the estimates of the time-invariant parameters of the state space system:

$$
\begin{gathered}
i_{t}=\frac{1}{1+\exp \left(-a_{5, t}\right)} i_{t-1}+\frac{\exp \left(-a_{5, t}\right)}{1+\exp \left(-a_{5, t}\right)}\left(a_{0, t}+a_{1, t} \pi_{t \mid t}+a_{2, t} \sigma_{\pi_{t} \mid t}^{2}+a_{3, t} y_{t \mid t}\right)+\exp \left(a_{4, t}\right) \varepsilon_{t}, \\
a_{k, t}=a_{k, t-1}+\exp \left(\sigma_{a_{k}}\right) \varepsilon_{a_{k}, t}, k=0,1, \ldots, 5 .
\end{gathered}
$$




\section{References}

Alcidi, C., A. Flamini, and A. Fracasso (2011): "Policy Regime Changes, Judgment and Taylor Rules in the Greenspan Era," Economica, 78, 89-107.

Andreasen, M. M. (2010): "How to Maximize the Likelihood Function for a DSGE Model," Computational Economics, 35, 127-154.

Bernanke, B. and J. Boivin (2003): "Monetary Policy in a Data-Rich Environment," Journal of Monetary Economics, 50, 525-546.

Blinder, A. (1998): Central Banking in Theory and Practice, MIT press.

Blinder, A. and R. Reis (2005): "Understanding the Greenspan Standard," Technical report, CEPS Working Papers.

Boivin, J. (2006): "Has U.S. Monetary Policy Changed? Evidence from Drifting Coefficients and Real-Time Data," Journal of Money, Credit and Banking, 38, 1149-1173.

Bollerslev, T. (1986): "Generalized Autoregressive Conditional Heteroskedasticity," Journal of Econometrics, 31, 307-327.

Born, B. and J. Pfeifer (2014): "Policy Risk and the Business Cycle," Journal of Monetary Economics, 68, 68-85.

Clarida, R., J. Galí, and M. Gertler (1999): "The Science of Monetary Policy: a New Keynesian Perspective," Journal of Economic Literature, 37, 1661-1707.

Clarida, R., J. Galí, and M. Gertler (2000): "Monetary Policy Rules and Macroeconomic Stability: Evidence and Some Theory," Quarterly Journal of Economics, 115, 147-180.

Cogley, T. and T. Sargent (2001): "Evolving Post-World War II US Inflation Dynamics," in B. Bernanke and K. Rogoff, eds., NBER Macroeconomics Annual, MIT Press, 331388.

Cogley, T. and T. Sargent (2005): "Drifts and Volatilities: Monetary Policies and Outcomes in the Post WWII US," Review of Economic dynamics, 8, 262-302.

Creal, D. (2012): "A Survey of Sequential Monte Carlo Methods for Economics and Finance," Econometric Reviews, 31, 245-296.

Cukierman, A. and S. Gerlach (2003): "The Inflation Bias Revisited: Theory and Some International Evidence," The Manchester School, 71, 541-565.

Dolado, J., R. María-Dolores, and M. Naveira (2005): "Are Monetary-Policy Reaction Functions Asymmetric?: The Role of Nonlinearity in the Phillips Curve," European Economic Review, 49, 485-503.

Dolado, J., R. María-Dolores, and F. Ruge-Murcia (2004): "Nonlinear Monetary Policy Rules: Some New Evidence for the US," Studies in Nonlinear Dynamics \& Econometrics, 8, 1-34.

Doucet, A. and A. Johansen (2009): "A Tutorial on Particle Filtering and Smoothing: Fifteen Years Later," in D. Crisan and B. Rozovskii, eds., Handbook of Nonlinear Filtering, Oxford University Press, 656-704.

Favero, C. A. and R. Rovelli (2003): "Macroeconomic Stability and the Preferences of the Fed: A Formal Analysis, 1961-98," Journal of Money, Credit, and Banking, 35, 545-556. 
Fernández-Villaverde, J., P. Guerrón-Quintana, and J. Rubio-Ramírez (2010): "Reading the Recent Monetary History of the US, 1959-2007," Technical report, NBER Working Papers.

Fernández-Villaverde, J., P. Guerrón-Quintana, and J. Rubio-Ramírez (2015): "Estimating Dynamic Equilibrium Models with Stochastic Volatility," Journal of Econometrics, 185, 216-229.

Galí, J. (2008): Monetary Policy, Inflation, and the Business Cycle: an Introduction to the New Keynesian Framework, Princeton University Press.

Gerberding, C., F. Seitz, and A. Worms (2005): "How the Bundesbank Really Conducted Monetary Policy," The North American Journal of Economics and Finance, 16, 277292.

Gerdesmeier, D. and B. Roffia (2005): "The Relevance of Real-time Data in Estimating Reaction Functions for the Euro Area," The North American Journal of Economics and Finance, 16, 293-307.

Gordon, N., D. Salmond, and A. Smith (1993): "Novel Approach to Nonlinear/nonGaussian Bayesian State Estimation," in Radar and Signal Processing, IEE Proceedings $F$, IET, 107-113.

Granger, C. (2008): "Non-Linear Models: Where Do We Go Next - Time Varying Parameter Models?" Studies in Nonlinear Dynamics \& Econometrics, 12, 1-11.

Hansen, N. (2011): "The CMA Evolution Strategy: A Tutorial," .

Justiniano, A. and G. Primiceri (2008): "The Time-Varying Volatility of Macroeconomic Fluctuations," American Economic Review, 98, 604-641.

Kim, C. and C. Nelson (2006): "Estimation of a Forward-Looking Monetary Policy Rule: A Time-Varying Parameter Model Using Ex-post Data," Journal of Monetary Economics, 53, 1949-1966.

Lee, K., N. Olekalns, and K. Shields (2013): "Meta Taylor Rules for the UK and Australia; Accommodating Regime Uncertainty in Monetary Policy Analysis Using Model Averaging Methods," The Manchester School, 81, 28-53.

Lubik, T. A. and F. Schorfheide (2004): "Testing for Indeterminacy: An Application to US Monetary Policy," American Economic Review, 190-217.

Luukkonen, R., P. Saikkonen, and T. Teräsvirta (1988): "Testing Linearity Against Smooth Transition Autoregressive Models," Biometrika, 75, 491-499.

Martin, C. and C. Milas (2010): "Testing the opportunistic approach to monetary policy," The Manchester School, 78, 110-125.

Meyer, L. H., E. T. Swanson, and V. W. Wieland (2001): "NAIRU Uncertainty and Nonlinear Policy Rules," American Economic Review, 91, 226-231.

Molodtsova, T., A. Nikolsko-Rzhevskyy, and D. H. Papell (2008): "Taylor Rules with Real-time Data: A Tale of Two Countries and One Exchange Rate," Journal of Monetary Economics, 55, 63-79.

Mumtaz, H. and F. Zanetti (2013): "The Impact of the Volatility of Monetary Policy Shocks," Journal of Money, Credit and Banking, 45, 535-558.

Nikolsko-Rzhevskyy, A. (2011): "Monetary Policy Estimation in Real Time: ForwardLooking Taylor Rules without Forward-Looking Data," Journal of Money, Credit and Banking, 43, 871-897. 
Nobay, R. and D. Peel (2003): "Optimal Discretionary Monetary Policy in a Model of Asymmetric Central Bank Preferences," Economic Journal, 113, 657-665.

Orphanides, A. (2001): "Monetary Policy Rules Based on Real-Time Data," American Economic Review, 91, 964-985.

Orphanides, A. (2002): "Monetary-Policy Rules and the Great Inflation," American Economic Review, 92, 115-120.

Orphanides, A. and D. Wilcox (2002): "The Opportunistic Approach to Disinflation," International Finance, 5, 47-71.

Primiceri, G. E. (2005): "Time Varying Structural Vector Autoregressions and Monetary Policy," The Review of Economic Studies, 72, 821-852.

Ristic, B., S. Arulampalm, and N. Gordon (2004): Beyond the Kalman Filter: Particle Filters for Tracking Applications, Artech House Publishers.

Romer, C. and D. Romer (1989): "Does Monetary Policy Matter? A New Test in the Spirit of Friedman and Schwartz," in O. Blanchard and S. Fisher, eds., NBER Macroeconomics Annual, MIT Press.

Rotemberg, J. J. and M. Woodford (1999): "Interest-Rate Rules in an Estimated Sticky Price Model," in J. Taylor, ed., Monetary policy rules, University of Chicago Press, 319-348.

Rudebusch, G. (2001): "Is the Fed too Timid? Monetary Policy in an Uncertain World," Review of Economics and Statistics, 83, 203-217.

Ruge-Murcia, F. (2003): "Does the Barro-Gordon Model Explain the Behavior of US Inflation? A Reexamination of the Empirical Evidence," Journal of Monetary Economics, 50, 1375-1390.

Sims, C. and T. Zha (2006): "Were There Regime Switches in US Monetary Policy?" American Economic Review, 96, 54-81.

Stock, J. and M. Watson (2007): "Why Has US Inflation Become Harder to Forecast?" Journal of Money, Credit and Banking, 39, 3-33.

Surico, P. (2007): "The Fed's Monetary Policy Rule and U.S. Inflation: The Case of Asymmetric Preferences," Journal of Economic Dynamics and Control, 31, 305-324.

Teräsvirta, T. (1994): "Specification, Estimation, and Evaluation of Smooth Transition Autoregressive Models," Journal of the American Statistical Association, 89, 208-218.

Teräsvirta, T. (2009): "An Introduction to Univariate GARCH Models," in Handbook of Financial Time Series, Springer, 17-42.

Teräsvirta, T. (2018 forthcoming): "Nonlinear models in macroeconometrics," in Oxford Research Encyclopedia in Economics and Finance, Oxford University Press.

Teräsvirta, T., D. Tjøstheim, and C. Granger (2010): Modelling Nonlinear Economic Time Series, Advanced Texts in Econometrics, Oxford University Press.

Tillmann, P. (2011): "Parameter Uncertainty and Nonlinear Monetary Policy Rules," Macroeconomic Dynamics, 15, 184-200.

Varian, H. (1975): "A Bayesian Approach to Real Estate Assessment," in S. Fienberg and A. Zellner, eds., Studies in Bayesian Econometrics and Statistics in Honor of Leonard J. Savage, North Holland, 195-208.

Woodford, M. (2001): "The Taylor Rule and Optimal Monetary Policy," American Economic Review, 91, 232-237. 
Woodford, M. (2003): Interest and Prices: Foundations of a Theory of Monetary Policy, Princeton University Press. 